\title{
Thyroid hormone actions on male reproductive system of teleost fish
}

\author{
Aldo Tovo-Neto ${ }^{\mathrm{a}, \mathrm{c}, \mathrm{d}}$, Maira da Silva Rodrigues ${ }^{\mathrm{c}, \mathrm{d}}$, Hamid R. Habibi ${ }^{\mathrm{a}, \mathrm{b}, *}$, \\ Rafael Henrique Nóbrega ${ }^{\mathrm{d}, *}$ \\ a Department of Biological Sciences, University of Calgary, Calgary, Alberta, Canada \\ ${ }^{b}$ Physiology and Pharmacology, University of Calgary, Calgary, Alberta, Canada \\ c Aquaculture Program, São Paulo State University (UNESP), Jaboticabal, São Paulo, Brazil \\ d Departament of Morphology, Reproductive and Molecular Biology Group, São Paulo State University (UNESP), Botucatu, São Paulo, Brazil
}

\section{A R T I C L E I N F O}

\section{Keywords:}

Thyroid hormones

Sex differentiation

Testicular development

Adult testis

Reproduction

Spermatogenesis

Teleost fish

\begin{abstract}
A B S T R A C T
Thyroid hormones (THs) play important roles in the regulation of many biological processes of vertebrates, such as growth, metabolism, morphogenesis and reproduction. An increasing number of studies have been focused on the involvement of THs in the male reproductive system of vertebrates, in particular of fish. Therefore, this minireview aims to summarize the main findings on THs role in male reproductive system of fish, focusing on sex differentiation, testicular development and spermatogenesis. The existing data in the literature have demonstrated that THs exert their roles at the different levels of the hypothalamic-pituitary-gonadal (HPG) axis. In general a positive correlation has been shown between THs and fish reproductive status; where THs are associated with testicular development, growth and maturation. Recently, the molecular mechanisms underlying the role of THs in spermatogenesis have been unraveled in zebrafish testis. THs promote germ cell proliferation and differentiation by increasing a stimulatory growth factor of spermatogenesis produced by Sertoli cells. In addition, THs enhanced the gonadotropin-induced androgen release in zebrafish testis. Next to their functions in the adult testis, THs are involved in the gonadal sex differentiation through modulating sex-related gene expression, and testicular development via regulation of Sertoli cell proliferation. In conclusion, this mini-review showed that THs modulate the male reproductive system during the different life stages of fish. The physiological and molecular mechanisms showed a link between the thyroid and reproduction, suggesting a possibly coevolution and interdependence of these two systems.
\end{abstract}

\section{Introduction}

Thyroid hormones (THs) have been known to be involved in many biological processes, such as growth, morphogenesis, skin pigmentation, osmoregulation, and reproduction (Blanton and Specker, 2007). An increasing number of studies has shown that THs exert an important role in male reproductive system of vertebrates. In the past two decades, experimental and clinical studies have shown the involvement of THs in the testicular development and function in mammals (Wagner et al., 2008). Similar functions were reported in other vertebrates, such as fish, which is the focus of this mini-review. The interaction between THs and fish reproductive system was reviewed before by Cyr and Eales (1996), Blanton and Specker (2007), Habibi et al. (2012) and Flood et al. (2013). While there are significant variations in the nature of interaction between THs and reproduction in different fish species, it would appear that THs may exert stimulatory and/or inhibitory actions by different mechanisms (Habibi et al., 2012). In this context, this minireview will address some of the direct and indirect actions of THs in male reproductive system of teleost fish, highlighting the main findings on sex differentiation, testicular development and adult testis.

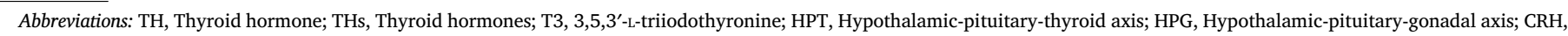

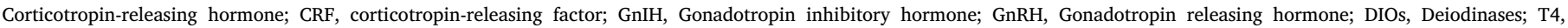

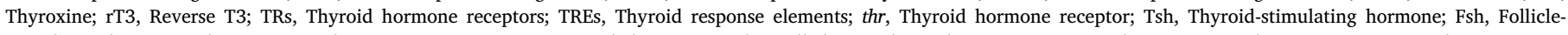

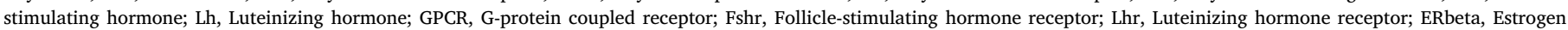

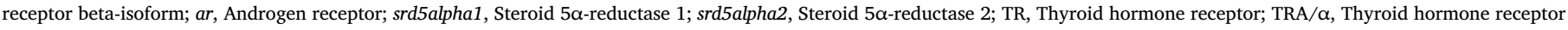

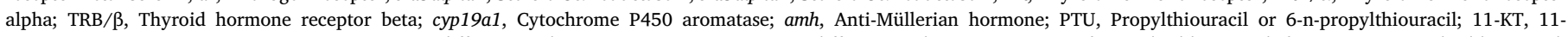

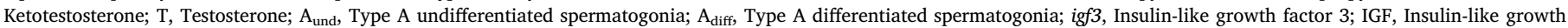

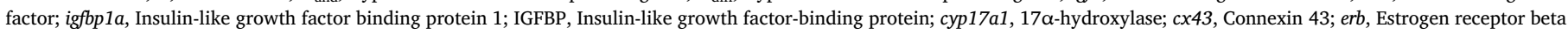

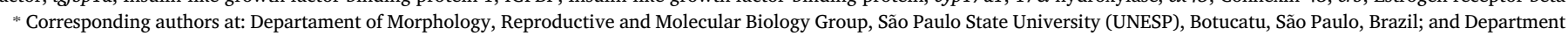
of Biological Sciences, University of Calgary, Calgary, Alberta, Canada.

E-mail address: nobregarh@ibb.unesp.br (R.H. Nóbrega).
} 
(a)

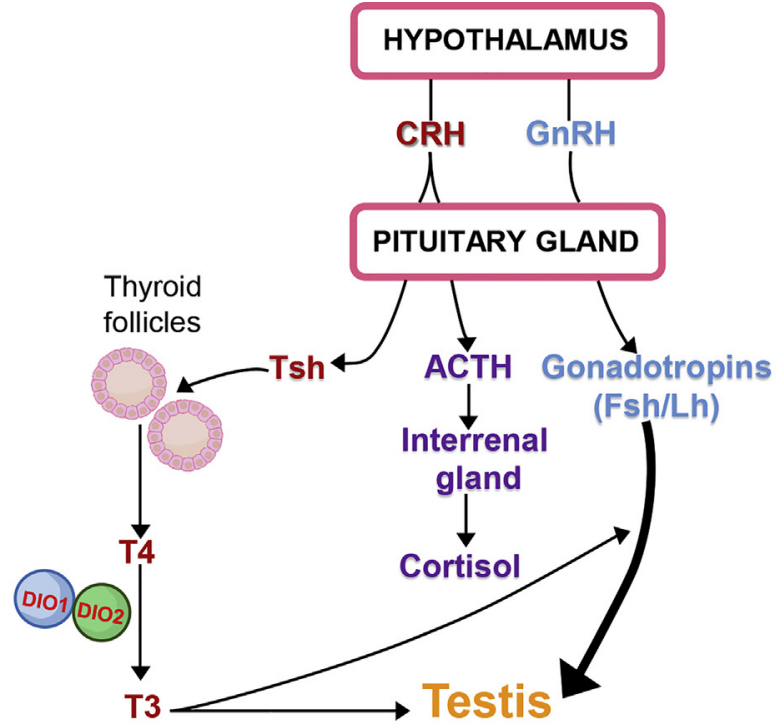

(b)

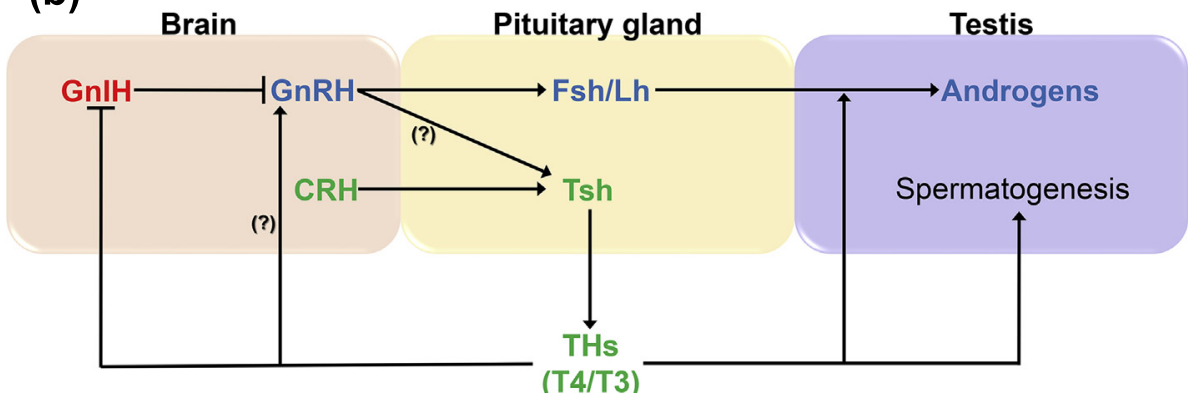

Fig. 1. A The hypothalamic-pituitary-thyroid, -interrenal, and -testicular axes in fish. The pituitary secretion of Tsh (thyroid-stimulating hormone) seems to be dependent on corticotropin-releasing hormone (CRH), similarly as observed in amphibians, reptiles and birds. CRH is also involved in the pituitary secretion of ACTH (adrenocorticotropic hormone), which stimulates the synthesis and secretion of cortisol by the interrenal gland. In the thyroid follicles, which are dispersed in fish, Tsh stimulates the production of $\mathrm{T} 4$, which is the main $\mathrm{TH}$ secreted. Two types of deiodinase (DIO1 and DIO2) convert T4 into $\mathrm{T} 3$ in the extrathyroidal tissues. T3, the active TH form, exerts its role in the testis, which are generally associated with testicular development, growth and maturation. Recent studies have shown that T3 enhanced the gonadotropins (Fsh, follicle-stimulating hormone; Lh, luteinizing hormone) function in the testis (enlarged arrow). B. The main effects of thyroid hormones (THs) in the hypothalamic-pituitary-testicular axis. In mammals, THs inhibit the synthesis of GnIH (Gonadotropin-releasing hormone) (Tsutsui et al., 2018). In tilapia, T3 suppressed the concentration of terminal nerve salmon GnRH mRNA in sexually immature males (Parhar et al., 2000). Other studies have demonstrated that GnRH increased Tsh (thyroid-stimulating hormone) and thyroid function in some species of fish and amphibians (Jacobs et al., 1988a,b; Roy et al., 2000; Chiba et al., 2004). In the testis, T3 stimulates spermatogenesis and enhances the gonadotropin-induced androgens synthesis and release. The question mark (?) indicates controversial data in the literature with respect to the reciprocal regulatory role between $\mathrm{GnRH}$ and thyroid function. $\mathrm{CRH}$, corticotropin-releasing hormone; Fsh, follicle stimulating hormone; Lh, Luteinizing hormone.

\section{Hypothalamic-pituitary-thyroid axis}

Thyroid function is activated by the hypothalamic-pituitary-thyroid axis (HPT), which has been reviewed in many vertebrates, including fish (Fig. 1A,B) (Brown and Cai, 2007; Blanton and Specker 2007; and Carr and Patiño, 2011). A particular characteristic of the HPT in fish is the non-involvement of thyrotropin releasing hormone (TRH) as occurs in mammals (Larsen et al., 1998). On the other hand, the pituitary secretion of TSH (Thyroid-stimulating hormone) seems to be dependent on corticotropin-releasing hormone ( $\mathrm{CRH}$, or known as corticotropinreleasing factor - CRF) (Fig. 1A,B) (Larsen et al., 1998), similarly as observed in amphibians, reptiles and birds (De Groef et al., 2003; Castañeda Cortés et al., 2014). The secreted TSH stimulates the synthesis and release of THs by thyroid follicles. In fish, the thyroid follicles are not encapsulated in an organ, but they are dispersed among the afferent branchial arterioles of the ventral region of pharynx (Cyr and Eales, 1996; Carr and Patiño, 2011). The L-Thyroxine (T4) is the main TH secreted under normal circumstances, while T3, known as the active hormone, is mostly produced by extrathyroidal sources from T4 conversion (Basset et al., 2003). The conversion of T4 into T3 is catalyzed by two distinct selenoenzymes, type 1 and type 2 deiodinases (DIO1 and DIO2, respectively) (Fig. 1A; Supplemental Fig. 1) (for review see Orozco et al., 2012).

The active form (T3) regulates nuclear gene expression by binding to the TH receptors (TRs), TR $\alpha$ and TR $\beta$. The TRs are encoded by THRA and THRB genes, which are transcribed as multiple mRNA isoforms. TR $\alpha 1, T R \alpha 2$, TR $\beta 1$ and TR $\beta 3$ are expressed widely whereas TR $\beta 2$ is predominantly restricted to the hypothalamic/pituitary axis, where it acts negatively to regulate TSH transcription (for a review see Basset et al., 2003). TRs act as transcription factors binding to TH response elements (TREs) in the regulatory regions of target genes, activating or repressing their transcription (Basset et al., 2003). In anamniotes (fish and amphibians), TH receptor (thr) is differentially expressed between testes and ovaries; higher thr mRNA levels were found in testes than in ovaries of striped parrotfish Scarus iseri (Johnson and Lema, 2011) and tropical clawed frog Silurana tropicalis (Duarte-Guterman and Trudeau, 2011). In zebrafish testes, thra mRNA was detected in Sertoli cells, while thr $\beta$ was detected in both Sertoli and Leydig cells (Morais et al., 2013). Interestingly, testicular thr $\alpha$ and thr $\beta$ mRNA levels in seasonally reproducing brook trout Salvelinus fontinalis are constant during the spermatogenesis, increasing their expression levels after the spawning season (de Montgolfier et al., 2009). The action of sex steroids on TRs is variable in different fish species. In goldfish, acute treatment with gonadal steroids had no effects on liver and gonadal thr $\alpha$ and thr $\beta$ mRNA in male and female fish, although developmentally-related changes in TRs expression occur in other fish species (Nelson and Habibi, 2009).

Another interesting aspect to be mentioned is the crossover of the HPT and the hypothalamic-pituitary-gonadal (HPG) axes (Castañeda Cortés et al., 2014) (Fig. 1B). Next to the well-known function of GnRH (Gonadotropin-releasing hormone) in regulating gonadotropins, GnRH has been shown to induce TSH secretion in amphibians (Denver, 1988; Okada et al., 2004). Other studies have demonstrated that GnRH exposure increased T4 plasma levels in freshwater murrel (Channa gachua) and in two species of carp (Roy et al., 2000), as well in barfin flounder (Verasper moseri), masu salmon (Oncorhynchus masou), goldfish (Carassius auratus) (Chiba et al., 2004), and amphibians (Jacobs et al., 1988a,b). However, no changes in T3 plasma levels were observed after injections of an analogue of GnRH in goldfish (MacKenzie et al., 1987). When evaluating the effects of THs on GnRH, studies on tilapia, Oreochromis niloticus, showed that $\mathrm{T} 3$ suppressed the concentration of 
terminal nerve salmon GnRH mRNA in sexually immature males (Fig. 1B) (Parhar et al., 2000). This fact is consistent with the hypothesis that $\mathrm{TH}$, by suppressing terminal nerve GnRH expression, promotes inhibition of sexual maturation in tilapia males (Parhar et al., 2000).

More recently, studies have been focused on GnIH (Gonadotropin inhibitory hormone), which is a newly discovered hypothalamic neuropeptide that inhibits the pituitary gonadotropin synthesis and release (Tsutsui et al., 2018). Interestingly, it has been shown that mammalian GnIH neurons express TR $\alpha$ and TR $\beta$ (Tsutsui et al., 2018). In addition, female mice with thyroid dysfunction showed higher levels of GnIH, and presented lower circulating levels of gonadotropins and estradiol, which might be associated with the delayed puberty (Tsutsui et al., 2018). These data suggest a possible role of THs on regulating the GnIH synthesis and release in vertebrates (Fig. 1B).

\section{Fish reproduction}

The relationship between thyroid function and reproduction has been explored for many years in different species. In fish, it is established that reproductive strategies vary greatly among the species (Eales, 2006), and it has become clear that the nature of interaction between TH and reproduction is highly species-specific (Habibi et al., 2012). Thyroidal function usually increases during early gonadal development in fish, and it is maintained or enhanced during the period of reproduction, and commonly decreased during or after spawning (Cyr and Eales, 1996). Similar function is seen in reptiles, birds and mammals, where TH administration induced testicular growth in thyroidectomized or short photoperiod-induced males (Haldar-Misra and Thapliyal, 1981; Yoshimura et al., 2003; Freeman et al., 2007).

Temporal relationship between thyroidal and reproductive status has been examined in some seasonal species of fish, in particular, nonsalmonids and salmonids (for review see Cyr and Eales, 1996). In nonsalmonids, a general positive correlation between thyroid activity and reproductive status has been seen among the species. On the other hand, thyroid function in Salmonidae is high in the early stages of gonadal maturation but decreases as vitellogenesis and testis development proceed. However, T3 plasma levels are higher in males than females just prior to spawning and may even increase (for review see Cyr and Eales, 1996). Table 1 summarizes selected data from the literature about the relationship between thyroid function and reproduction in non-mammalian and mammalian vertebrates. Therefore, the summarized data in the literature suggest that the basic function for THs is associated with gonadal maturation in fish as well as in other vertebrates.

\section{Sex differentiation}

THs have considerable influence on the sexual ontogeny of male vertebrates, through direct interactions with genes involved in sex determination and gonadal development along the HPG axis (Flood et al., 2013). The role of THs in the establishment of gonadal sex phenotype has been previously examined in amphibians and reptiles. For example, chronic treatment with $\mathrm{TH}$ synthesis inhibitors (perchlorate or thiourea) during larval development resulted in a feminization effect in Xenopus laevis (Goleman et al., 2002; Hayes, 1997). In another study, premetamorphic tadpoles (Nieuwkoop and Faber stage 52-54) were exposed to exogenous $\mathrm{T} 3$ for $48 \mathrm{~h}$ and resulted in a concentration-dependent decrease of estrogen receptor beta isoform (ERbeta) expression at concentrations of 5 and $50 \mathrm{nM} \mathrm{T3}$. The expression of androgen-related genes also changed and significantly increased following treatment with T3 in relation to the control. Treatment with T3 also led to changes in ar (androgen receptor, 1.4-1.8 fold), srd5alpha1 (steroid 5 $\alpha$ reductase $1 ; 1.5-1.9$ fold) and srd5alpha2 (steroid $5 \alpha$-reductase 2; 1.8-3.9 fold) in tropical clawed frogs (Duarte-Guterman and Trudeau, 2011). In reptiles, hyperthyroid treatment decreased cyp19a1 transcripts (gonadal aromatase), and consequently estradiol levels, inducing therefore more male offspring in a TSD (Temperature-dependent sex determination) turtle (Trachemys scripta) (Sun et al., 2016).

In fish and amphibians, an evidence that THs are involved in gonadal sex differentiation is the different expression of deiodinases and thr between males and females, as reported in striped parrotfish, Scarus iseri (Johnson and Lema, 2011) and tropical clawed frog Silurana tropicalis (Duarte-Guterman and Trudeau, 2011). In addition, An et al. (2010) observed a decrease in gonadal thro expression in protandrous

Table 1

Selected experimental results correlating thyroid status and reproduction in vertebrates.

\begin{tabular}{|c|c|c|}
\hline Species & Treatment & Effects \\
\hline & Stimulated thyroid function & Coincides with sexual maturation \\
\hline & Elevated TH plasma levels & Occurs during gonadal maturation \\
\hline & Goitrogen exposure & Gonadal atrophy in both sexes \\
\hline & Presence of goiters in salmon from Great Lakes & Associated with low egg production; low gonadal steroid levels in blood \\
\hline \multicolumn{3}{|c|}{ Amphibians } \\
\hline & Treatment with thyroxine of thyroidectomized frogs & Permits ovulation \\
\hline & Treatment of anuran liver with $\mathrm{TH}$ & Enhances action of estrogen on vitellogenesis \\
\hline & Thyroid function & Not associated with reproductive activities \\
\hline & Goitrogen treatment of tadpoles (anurans) & Prevents testicular development \\
\hline & Elevated thyroxine in the blood of salamanders & Coincides with gonadal growth in males and females \\
\hline \multicolumn{3}{|l|}{ Reptiles } \\
\hline & Thyroxine treatment & Atrophy of steroid secreting cells in testes \\
\hline & Thyroidectomized males & Testicular regression \\
\hline \multicolumn{3}{|c|}{ Mammals } \\
\hline & Exogenous T3 & Induced gonadal growth in short-day hamsters \\
\hline & Exogenous $\mathrm{T} 3$ & Delayed testicular regression in short photoperiod-induced males \\
\hline
\end{tabular}

Adapted from Norris (2006).

* TH, Thyroid Hormones. 


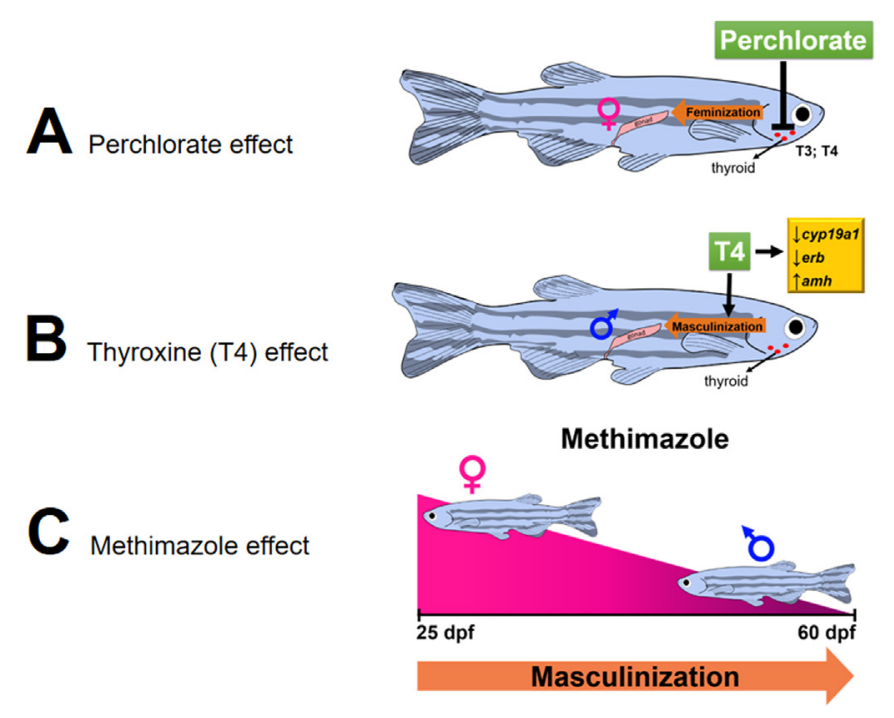

black porgy (Acanthopagrus schlegeli) following male-to-female sex reversal. During zebrafish metamorphosis and early gonadal development, treatment with perchlorate (a well-known thyroid synthesis inhibitor), significantly skewed the sex ratio toward females (Fig. 2A) (Mukhi et al., 2007). However, the co-treatment with exogenous T4 not only blocked the feminizing effect of perchlorate but also overcompensated by skewing the ratio toward males. In another study, Sharma and Patiño (2013) showed that either perchlorate or methimazole (an antithyroid drug) induced feminization in zebrafish larvae at $45 \mathrm{dpf}$ (days post-fertilization). Interestingly, the feminizing effect was still present in the perchlorate treatment, but not anymore in methimazole treatment at $60 \mathrm{dpf}$, suggesting that the effect disappeared as fish regained the euthyroid conditions. The conclusion is that methimazole does not cause male-to-female sex reversal but simply delays the ovary-to-testis transformation in presumptive males of this species (Fig. 2C). It is worth emphasizing that studies using antithyroid drugs can provide a powerful tool for understanding TH function but only with an appropriate control due to the extrathyroidal effects these drugs can have. A rigorous study requires a follow up to determine if those effects can be nullified or reversed by simultaneous administration of sufficient TH to regain euthyroid condition.

Interestingly, and more recently, Sharma et al. (2016) evaluated the molecular mechanisms involved in T4-induced masculinization in zebrafish larvae. These authors demonstrated that $\mathrm{T} 4$ treatment decreases cyp19a1 (aromatase) and estrogen receptor expression, while increasing expression of masculinizing transcripts, such as amh (antiMüllerian hormone) and ar (androgen receptor) (Sharma et al., 2016) (Fig. 2B).

\section{Testicular development}

In rodents, THs affect Sertoli cell proliferation and differentiation (Fig. 3A), as well as the onset of adult Leydig cell formation and function during neonatal-prepubertal period (Teerds et al., 1998; Ariyaratne et al., 2000). Induced-hypothyroidism in the neonatal rat impaired testicular growth, germ cell maturation, seminiferous tubule formation and other differentiation processes in the testis (França et al., 1995; Maran et al., 2002). Induced-neonatal hypothyroidism has also been shown to increase Sertoli cell proliferative window, which consequently increased Sertoli number and the Sertoli cell support capacity for germ cells, reflecting directly on the elevated spermatic yield and testis size (Fig. 3A) (Cooke et al., 1991). Interestingly, the impairment caused by neonatal induced-hypothyroidism in rats was rescued with T3 (Cooke et al., 1991). On the other hand, hyperthyroidism led to

\section{Sex ratio}

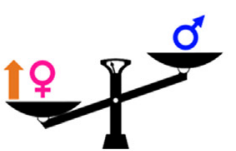

Fig. 2. Effects of thyroid hormones during sex differentiation of fish. (A) Treatment with perchlorate induces feminization in early gonadal development, skewing the sex ratio toward females. (B) Treatment with T4 induces masculinization in early gonadal development by reducing the expression of cyp19a1 (aromatase) and erb (estrogen receptor beta) and increasing amh (anti-Müllerian hormone). T4 increases the ratio of females. (C) Methimazole treatment delays masculinization from females during the early developmental stage of zebrafish. Sex ratio is $1: 1$.
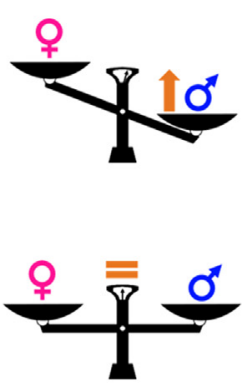

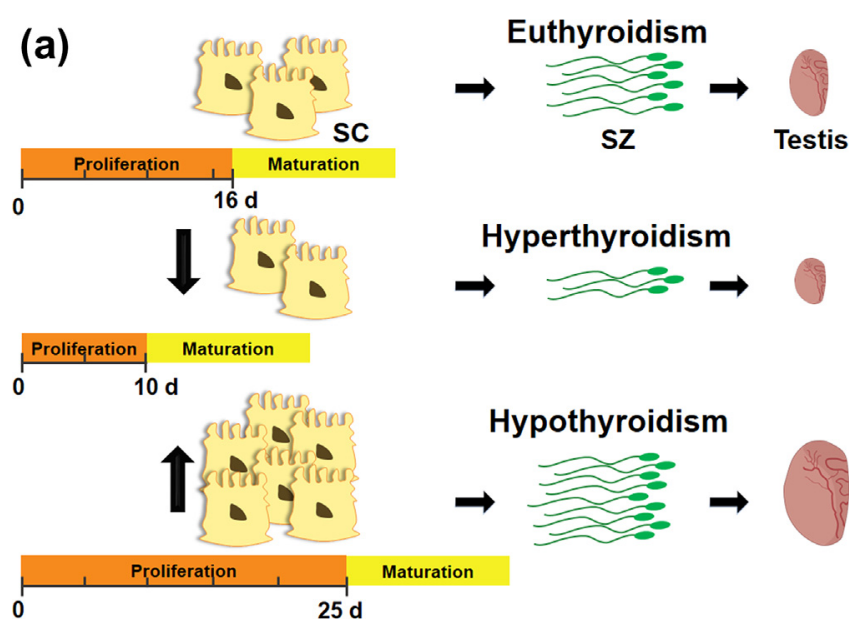

(b)

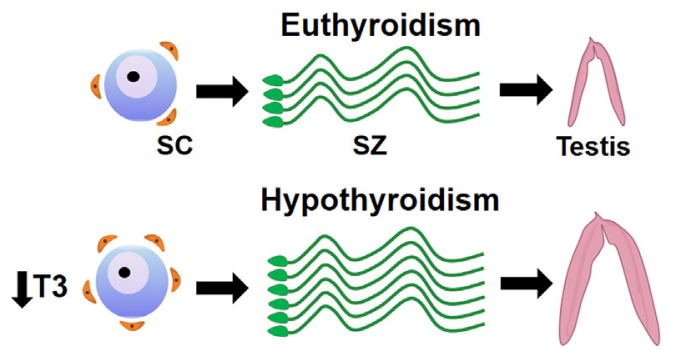

Fig. 3. (A) Effects of hypothyroidism and hyperthyroidism on testicular development in rodents. The induced-hyperthyroidism decreased the Sertoli cell proliferative window, reflecting directly on the final number of adult Sertoli cell, and consequently in the lower spermatic yield and testis size/weight. On the other hand, Sertoli cell differentiation is delayed in the hypothyroidism model, increasing their proliferative window. In consequence, there is an elevated number of adult Sertoli cell which leads to higher sperm production and testis size/weight. SC: Sertoli cell; SZ: spermatozoa. (B) Effects of hypothyroidism on testicular development in fish. PTU-induced hypothyroidism increased Sertoli cell proliferation and Sertoli cell capacity reflecting directly on higher number of germ cells per cyst. In this model, higher sperm production and testis weight are seen. SC: Sertoli cell; SZ: spermatozoa.

early cessation of Sertoli cell proliferation, and a decrease in testis size and sperm production in rats (Fig. 3A) (van Haaster et al., 1993; Cooke et al., 1994a,b; Mendis-Handagma and Ariyaratne, 2005).

There are few papers describing the effects of hypothyroid state on 
testicular development in fish (see review in Schulz et al., 2010; França et al., 2015). According to Matta et al. (2002), Nile tilapia (Oreochromis niloticus) juveniles ( $\sim 0.95 \mathrm{~g}$ body weight and $3.5 \mathrm{~cm}$ of length) treated with PTU (propylthiouracil, anti-thyroid drug similar to methimazole) doubled the size of testis which is similar to the effects observed in rats, suggesting that mechanisms controlling testicular development by THs may be conserved among vertebrates. In hypothyroid Nile tilapia, Sertoli cells remained immature and were able to proliferate for longer period during testis development, resulting in a higher number of Sertoli cell (Matta et al., 2002) (Fig. 3B). The increased number of Sertoli cell per cyst reflected positively on Sertoli cell capacity and efficiency and consequently in the germ cell number in adult tilapia (Fig. 3B) (Matta et al., 2002; França et al., 2015). Sharma and Patiño (2013) reported that goitrogen (e.g. perchlorate) exposure inhibited pubertal development in male zebrafish, as clearly seen at $60 \mathrm{dpf}$. In the same work, all control and T4-treated males were mature $(>75 \%$ of them showed sperm in their testes), while those that were goitrogentreated were still juvenile and less than $50 \%$ had sperm. In contrast, Timmermans et al. (1997) observed no significant increase in body weight and testis diameter or number of spermatogonia following treatment with T4 in two strains of juvenile common carp (Cyprinus carpio).

\section{Adult testis}

Although there is a general agreement that THs are important regulators of the testicular development prior to and during puberty in mammals, the role of these hormones is not very clear in the adult testis (Wagner et al., 2009). Considering that most of the experimental studies to date are focused on TH effects on the developing testes, only limited data are available on its role in vertebrate spermatogenesis (Wagner et al., 2009; Morais et al., 2013; Safian et al., 2016).

Altered thyroid status, natural or experimentally induced, is frequently associated with some sort of sexual dysfunction and/or morphological testicular alteration in mammals (Faraone-Menella et al., 2008). Similar studies in reptiles showed that thyroidectomy impaired spermatogenesis of adult garden lizards (Calotes versicolor), while T4 treatment nullified the thyroidectomy-induced testicular atrophy (Haldar-Misra and Thapliyal, 1981). In adult catfish (at early recrudescence/early preparatory phase), treatment with thiourea (a thyroid disrupter) reduced androgen plasma and tissue levels after thyroid depletion, leading to a male reproductive system disruption (Swapna et al., 2006). Interestingly, thiourea treatment withdrawal for 21 days induced a partial recovery of androgen levels, which indicates that thyroid plays a role in maintaining testis functions via androgen stimulation (Swapna et al., 2006). In this context, it has been observed that androgens could also regulate thyroid function. Testosterone propionate injected intramuscularly in immature rainbow trout (Salmo gairdneri Richardson) stimulates, directly or indirectly, the thyroid function, increasing T3 plasma levels (Hunt and Eales, 1979).

To study the effects of THs on fish spermatogenesis, a different experimental setting was employed, where African catfish (Clarias gariepinus) received T4 (100 ppm) for 21 days (Jacob et al., 2005). In this study, T4 depleted the number of spermatozoa/spermatids during the preparatory and pre-spawning phases (Jacob et al., 2005). Interestingly, the T4 overdose effects were more pronounced during the preparatory phase rather than pre-spawning, suggesting that altered $\mathrm{TH}$ status might have significant stage-dependent effects on the testis.

More recently, Morais et al. (2013) studied the effects of THs on zebrafish spermatogenesis using an ex vivo approach. These authors showed that $\mathrm{T} 3$ increased both mitotic index of type A undifferentiated spermatogonia $\left(\mathrm{A}_{\text {und }}\right)$ and Sertoli cell in zebrafish testis. In the follow up experiments, Safian et al. (2016) demonstrated that T3 not only promoted the formation of new cysts with type $A_{\text {und }}$ spermatogonia, but also stimulated the accumulation of $\mathrm{A}_{\text {diff }}$ (type $\mathrm{A}$ differentiated spermatogonia) by increasing their proliferation while reducing

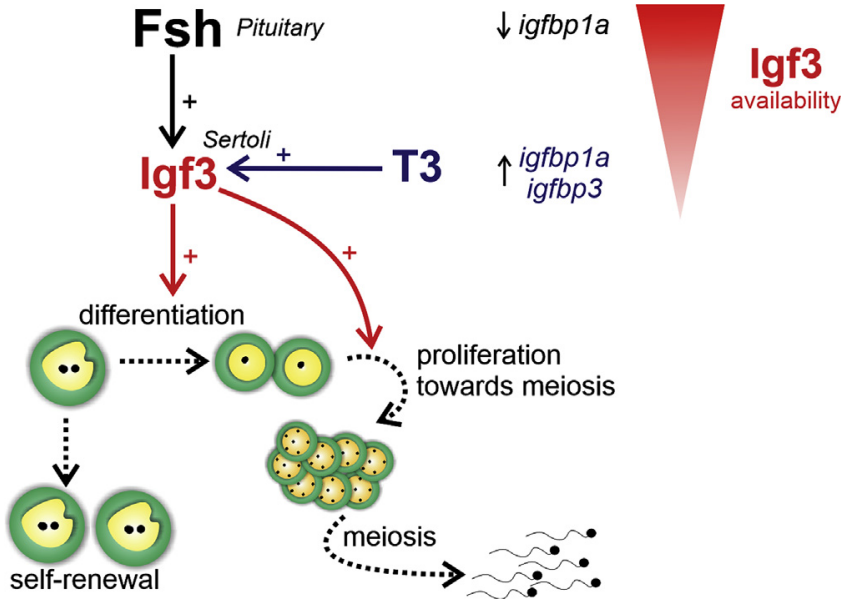

Fig. 4. Endocrine and paracrine regulation of spermatogonial proliferation in zebrafish. Fsh (follicle-stimulating hormone) and T3 stimulate the production of Igf3 (Insulin-like growth factor 3), which in turn promotes spermatogonial differentiation and proliferation towards meiosis. Igf3 is produced by Sertoli cells. T3 increases the transcript levels of two igfbps (insulin-like growth factor binding protein): igfbp1a and igfbp3. Fsh decreases RNAm levels of igfbp1a. The differential expression of the igfbps reflects directly on the Igf3 availability. Elevating Igf3 bioactivity by blocking Igfbps induced by T3 results in a excessive spermatogonial differentiation, leading to a depletion of type $A_{\text {und }}$ spermatogonia in zebrafish.

development into type B spermatogonia in zebrafish (Fig. 4).

To unravel the molecular mechanisms of THs on zebrafish spermatogenesis, Morais et al. (2013) first showed the localization of thra and $t h r \beta$ in Sertoli and Leydig cells, respectively. Similar data have been found in mammals, where TRs are localized in Sertoli cells, although these receptors were also found in mammalian germ cells (Buzzard et al., 2000; Singh et al., 2011). Moreover, it has been demonstrated that T3 increased a stimulatory growth factor of spermatogenesis, named Igf3 (Insulin-like growth factor 3) (Fig. 4) (Morais et al., 2013). Igf3 is a Sertoli cell growth factor, exclusively expressed in zebrafish gonads, and Fsh (Follicle-stimulating hormone) responsive (Fig. 4) (Nóbrega et al., 2015). It has been shown that Fsh promotes spermatogonial proliferation and differentiation via Igf3 in zebrafish testis (Nóbrega et al., 2015), which is consistent with T3 stimulation of spermatogonial proliferation and differentiation in this species (Fig. 4) (Morais et al., 2013). Interestingly, co-treatment with T3 and an IGF receptor inhibitor abolished the observed $\mathrm{T} 3$ effects on zebrafish spermatogenesis. Altogether, these results suggest that T3 stimulates zebrafish spermatogonial proliferation and differentiation via Sertoli cell production of Igf3 (Fig. 4) (Morais et al., 2013).

More recently, another study in zebrafish testis showed that T3 not only stimulates Igf3, but also increased the transcript levels of igfbp1a (Insulin-like growth factor binding protein 1) and igfbp3 (Insulin-like growth factor binding protein 3) (Fig. 4) (Safian et al., 2016). In this study, Safian et al. (2016) showed a depletion of type $A_{\text {und }}$ spermatogonia in zebrafish testis treated with T3 when neutralizing the Igfbps, suggesting that Igfbps protect undifferentiated spermatogonia against excessive differentiation (Fig. 4).

Next to their roles in Sertoli cells, THs also regulate Leydig cell functions in zebrafish testis (Fig. 4) (Morais et al., 2013). It is well known that Leydig cells express Fsh receptor, and Fsh is a potent steroidogenic hormone in zebrafish testis (Nóbrega et al., 2015). In this context, the Fsh steroidogenic capacity is increased in the presence of T3 in zebrafish testis (Morais et al., 2013). The observed increase in androgen secretion by zebrafish testis was accompanied by higher levels of ar and cyp17a1 (17 $\alpha$-hydroxylase/1720 lyase/1720 desmolase) mRNA levels, suggesting that Fsh effects are enhanced in the presence of T3 (Figs. 1 and 4). 
In another study evaluating the action of THs in adult testis, de Montgolfier et al. (2009) examined testicular connexin 43 (cx43) mRNA in brook trout (Salvelinus fontinalis) and demonstrated a clear dose-response relationship between $\mathrm{T} 3$ and $c x 43$, suggesting a possible regulation of this connexin by T3. These authors also investigated seasonal changes in the basal expression of several connexins and demonstrated higher levels of testicular $c \times 43$ in maturing fish, suggesting that changes in the connexins expression may precede the onset of spermatogenesis in this species.

\section{Summary}

In summary, this mini-review highlighted the main findings on THs role in male reproductive system of fish, focusing on sex differentiation, testicular development and spermatogenesis. The existing data in the literature have been demonstrated that THs exert their roles at the different levels of the HPG axis. In general, it has been shown a positive correlation between THs and fish reproductive status, where THs are frequently associated with testicular development, growth and maturation. More recently, the molecular mechanisms underlying the role of THs in spermatogenesis have been elucidated in the zebrafish testis model. In this model, ex vivo studies showed that T3 increases the Sertoli cell production of Igf3, which is a stimulatory growth factor of spermatogenesis. Moreover, T3 acts through Leydig cells to enhance the gonadotropin-induced synthesis and release of androgens. Next to their roles in the adult testis, THs also participate in the gonadal sex differentiation by regulating the expression of sex-related genes, and during testicular development through modulating Sertoli cell proliferation. Based on the evidences from the literature, it can be concluded that THs modulate the male reproductive system during the different life stages of fish. The physiological and molecular mechanisms showed a link between the thyroid and reproduction, suggesting a possibly co-evolution of these two systems. However, how crucial these systems are to each other remains a topic for future investigation.

\section{Acknowledgements}

The authors would like to thank Mr. Rodrigo Augusto Paixão Brasiliano for drawing the scientific illustrations of this mini-review. This work was supported by National Council for Scientific and Technological Development (CNPq) - Science without Borders (234548/2014-2) (awarded to Aldo Tovo-Neto) and FAPESP (2014/ 16280-5 and 2017/09218-0 - granted to Aldo Tovo-Neto; 2014/076207 - granted to Dr. Rafael Henrique Nóbrega; 2017/15793-7 granted to Maira da Silva Rodrigues).

\section{Appendix A. Supplementary data}

Supplementary data associated with this article can be found, in the online version, at https://doi.org/10.1016/j.ygcen.2018.04.023.

\section{References}

An, K.W., An, M.I., Nelson, E.R., Habibi, H.R., Choi, C.Y., 2010. Gender-related expression of TR alpha and TR beta in the protandrous black porgy, Acanthopagrus schlegeli, during sex change processes. Gen. Comp. Endocrinol. 165, 11-18.

Ariyaratne, H.B.S., Mason, J.I., Mendis-Handagama, S.M.L.C., 2000. Effects of thyroid and luteinizing hormones on the onset of precursor cell differentiation into leydig progenitor cells in the prepubertal rat testis. Biol. Reprod. 63, 898-904.

Basset, J.H.D., Harvey, C.B., Williams, G.R., 2003. Mechanisms of thyroid hormone receptor-specific nuclear and extra nuclear actions. Mol. Cell. Endocrinol. 213, 1-11.

Blanton, M.L., Specker, J.L., 2007. The hypothalamic-pituitary-thyroid (HPT) axis in fish and its role in fish development and reproduction. Crit. Rev. Toxicol. 37, 97-115.

Brown, D.D., Cai, L.Q., 2007. Amphibian metamorphosis. Dev. Biol. 306, 20-33.

Buzzard, J.J., Morrison, J.R., O’Bryan, M.K., Song, Q., Wreford, N.G., 2000.

Developmental expression of thyroid hormone receptors in the rat testis. Biol. Reprod. 62, 664-669.

Carr, J.A., Patiño, R., 2011. The hypothalamus-pituitary-thyroid axis in teleosts and amphibians: endocrine disruption and its consequences to natural populations. Gen.
Comp. Endocrinol. 170, 299-312.

Castañeda Cortés, D.C., Langlois, V.S., Fernandino, J.I., 2014. Crossover of the hypothalamic pituitary-adrenal/interrenal, -thyroid, and -gonadal axes in axes in testicular development. Front. Endocrinol. 139, 1-11.

Chiba, H., Amano, M., Yamada, H., Fujimoto, Y., Ojima, D., Okuzawa, K., Yamanome, T., Yamamori, K., Iwata, M., 2004. Involvement of gonadotropin-releasing hormone in thyroxine release in three different forms of teleost fish: barfin flounder, masu salmon and goldfish. Fish Physiol. Biochem. 30, 267-273.

Cooke, P.S., 1991. Thyroid hormones and testis development: a model system for increasing testis growth and sperm production. Ann. N. Y. Acad. Sci. 637, 122-132.

Cooke, P.S., Hess, R.A., Kirby, J.D., 1994a. A model system for increasing testis size and sperm production: potential application to animal science. J. Animal Sci. 72, 43-54.

Cooke, P.S., Zhao, Y.D., Bunick, D., 1994b. Triiodothyronine inhibits proliferation and stimulates differentiation of cultured neonatal Sertoli cells: possible mechanism for increased adult testis weight and sperm production induced by neonatal goitrogen treatment. Biol. Reprod. 51, 1000-1005.

Cyr, D.G., Eales, J.G., 1996. Interrelationships between thyroidal and reproductive endocrine systems in fish. Rev. Fish Biol. Fish. 6, 165-200.

Denver, R.J., 1988. Several hypothalamic peptides stimulate in vitro thyrotropin secre tion by pituitaries of anuran amphibians. Gen. Comp. Endocrinol. 72, 383-393.

Duarte-Guterman, P., Trudeau, V.L., 2011. Transcript profiles and triiodothyronine regulation of sex steroid- and thyroid hormone-related genes in the gonad-mesonephros complex of Silurana tropicalis. Mol. Cell. Endocrinol. 331, 143-149.

Eales, J.G., 2006. Modes of action and physiological effects of thyroid hormones in fish, in: Reinecke, M., Zaccone, G., Kapoor, B.G. (Eds). Fish Endocrinology. 2, pp. 767-808.

Faraone-Mennella, M.R., Ferone, A., Marino, L., Cardone, A., Comitato, R., Venditti, P., Di Meo, S., Farina, B., 2008. Poly(ADP-ribosyl)ation of proteins and germ cell development in hyperthyroid rat testes. Mol. Cell. Biochem. 323, 119-129.

Flood, D.E.K., Fernandino, J.I., Langlois, V.S., 2013. Thyroid hormones in male reproductive development: Evidence for direct crosstalk between the androgen and thyroid hormone axes. Gen. Comp. Endocrinol. 192, 2-14.

França, L.H., Hess, R.A., Cooke, P.S., Russell, L.D., 1995. Neonatal hypothyroidism causes delayed sertoli cell maturation in rats treated with propylthiouracil: evidence that the Sertoli cell controls testis growth. Anat. Rec. 242, 57-69.

França, L.R., Nóbrega, R.H., Morais, R.D.V.S., Assis, L.H.C., Schulz, R.W., 2015. Sertoli cell structure and function in anamniote vertebrates. In: Griswold, M.D. (Ed.), Sertoli Cell Biology. Elsevier, Amsterdam, pp. 385-407.

Freeman, D.A., Teubner, B.J., Smith, C.D., Prendergast, B.J., 2007. Exogenous T3 mimics long day lengths in Siberian hamsters. Am. J. Physiol. Regul. Integr. Comp. Physiol. 292, R2368-R2372.

Goleman, W.L., Carr, J.A., Anderson, T.A., 2002. Environmentally relevant concentrations of ammonium perchlorate inhibit thyroid function and alter sex ratios in developing Xenopus laevis. Environ. Toxicol. Chem. 21, 590-597.

De Groef, B., Goris, N., Arckens, L., Kühn, E.R., Darras, V.M., 2003. Corticotropin-releasing hormone (CRH)-induced thyrotropin release is directly mediated through CRH receptor type 2 on thyrotropes. Endocrinology 144, 5537-5544.

van Haaster, L.H., de Jong, F.H., Docter, R., de Rooji, D.G., 1993. High neonatal triiodothyronine levels reduce the period of Sertoli cell proliferation and accelerate tubular lumen formation in the rat testis, and increase serum inhibin levels. Endocrinology 133, 755-760.

Habibi, H.R., Nelson, E.R., Allan, E.R.O., 2012. New insights into thyroid hormone function and modulation of reproduction in goldfish. Gen. Comp. Endocrinol. 175, $19-26$.

Haldar-Misra, C., Thapliyal, J.P., 1981. Thyroid in reproduction of reptiles. Gen. Comp. Endocrinol. 43, 537-542.

Hayes, T.B., 1997. Steroids as potential modulators of thyroid hormone activity in anuran metamorphosis. Am. Zool. 37, 185-194.

Hunt, D.W.C., Eales, J.G., 1979. The influence of testosterone propionate on thyroid function of immature rainbow trout, Salmo gairdneri richardson. Gen. Comp. Endocrinol. 37, 115-121.

Jacob, T.N., Pandey, J.P., Raghuveer, K., Sreenivasulu, G., Gupta, A.D., Yoshikuni, M. Jagota, A., Senthilkumaran, B., 2005. Thyroxine-induced alterations in the testis and seminal vesicles of air-breathing catfish Clarias gariepinus. Fish Physiol. Biochem. 31, 271-274.

Jacobs, G.F.M., Goyvaerts, M.P., Vandorpe, G., Quaghebeur, A.M.L., Kuhn, E.R., 1988a. Luteinizing hormone-releasing hormone as a potent stimulator of the thyroidal axis in ranid frogs. Gen. Comp. Endocrinol. 70, 274-283.

Jacobs, G.F.M., Michielsen, R.P., Kuhn, E.R., 1988b. Thyroxine and triiodothyronine in plasma and thyroids of the neotenic and metamorphosed axolotl Ambystoma mexicanum: influence of TRH injections. Gen. Comp. Endocrinol. 70, 145-151.

Johnson, K.M., Lema, S.C., 2011. Tissue-specific thyroid hormone regulation of gene transcripts encoding iodothyronine deiodinases and thyroid hormone receptors in striped parrotfish (Scarus iseri). Gen. Comp. Endocrinol. 172, 505-517.

Larsen, D.A., Swanson, P., Dickey, J.T., Rivier, J., Dickhoff, W.W., 1998. In Vitro thyrotropin-releasing activity of corticotropin-releasing hormone-family peptides in coho salmon, Oncorhynchus kisutch. Gen. Comp. Endocrinol. 109, 276-285.

MacKenzie, D.S., Sokolowska, M., Peter, R.E., Breton, B., 1987. Increased gonadotropin levels in goldfish do not result in alterations in circulating thyroid hormone levels. Gen. Comp. Endocrinol. 67, 202-213.

Maran, R.R.M., Aruldhas, M.M., 2002. Adverse effects of neonatal hypothyroidism on Wistar rat spermatogenesis. Endocr. Res. 28, 141-154.

Matta, S.L.P., Vilela, D.A.R., Godinho, H.P., Franç, L.R., 2002. The goitrogen 6-n-propyl2-thiouracil (PTU) given during testis development increases sertoli and germ cell numbers per cyst in fish: the tilapia (Oreochromis niloticus) model. Endocrinology 143 970-978. 
Mendis-Handagama, S.M.L.C., Ariyaratne, H.B.S., 2005. Leydig cells, thyroid hormones and steroidogenesis. Indian J. Exp. Biol. 43, 939-962.

de Montgolfier, B., Faye, A., Audet, C., Cyr, D.G., 2009. Seasonal variations in testicular connexin levels and their regulation in the brook trout, Salvelinus fontinalis. Gen. Comp. Endocrinol. 162, 276-285.

Morais, R.D.V.S., Nóbrega, R.H., Gómez-Gonzáles, N.E., Schmidt, R., Bogerd, J., França, L.R., Schulz, R.W., 2013. Thyroid hormone stimulates the proliferation of sertoli cells and single type a spermatogonia in adult zebrafish (Danio rerio) Testis. Endocrinology 154, 4635-4676.

Mukhi, S., Patiño, R., 2007. Effects of prolonged exposure to perchlorate on thyroid and reproductive function in zebrafish. Toxicol. Sci. 96, 246-254.

Nelson, E.R., Habibi, H.R., 2009. Thyroid receptor subtypes: structure and function in fish. Gen. Comp. Endocrinol. 161, 90-96.

Nóbrega, R.H., Morais, R.D.V.S., Crespo, D., de Waal, P.P., França, L.R., Schulz, R.W., Bogerd, J., 2015. Fsh stimulates spermatogonial proliferation and differentiation in zebrafish via Igf3. Endocrinology 156, 3804-3817.

Norris, D.O., 2006. The Hypothalamus-Pituitary-Thyroid (HPT) Axis of Non-mammalian Vertebrates. In: Norris, D.O. (Ed.), Vertebrate Endocrinology. Elsevier, Amsterdam, pp. 244-270.

Okada, R., Yamamoto, K., Koda, A., Ito, Y., Hayashi, H., Tanaka, S., Hanaoka, Y., Kikuyama, S., 2004. Development of radioimmunoassay for bullfrog thyroid-stimulating hormone (TSH): effects of hypothalamic releasing hormones on the release of TSH from the pituitary in vitro. Gen. Comp. Endocrinol. 135, 42-50.

Orozco, A., Valverde, C.R., Olvera, A., García, C.G., 2012. Iodothyronine deiodinases: functional and evolutionary perspective. J. Endocrinol. 215, 207-219.

Parhar, I.S., Soga, T., Sakuma,, 2000. Thyroid hormone and estrogen regulate brain region specific messenger ribonucleic acids encoding three gonadotropin-releasing hormone genes in sexually immature male fish, Oreochromis niloticus. Endocrinology $141,1618-1626$.

Roy, P., Datta, M., Dasgupta, S., Bhattacharya, S., 2000. Gonadotropin-releasing hormone stimulates thyroid activity in a freshwater murrel, Channa gachua (Ham.), and Carps, Catla catla (Ham.) and Cirrhinus mrigala (Ham.). Gen. Comp. Endocrinol. 117, 456-463.

Safian, D., Morais, R.D.V.S., Bogerd, J., Schulz, R.W., 2016. Igf Binding proteins protect undifferentiated spermatogonia in the zebrafish testis against excessive differentiation. Endocrinology 157, 4423-4433.

Sharma, P., Patiño, R., 2013. Regulation of gonadal sex ratios and pubertal development by the thyroid endocrine system in zebrafish. Gen. Comp. Endocrinol. 184, 111-119.

Sharma, P., Tang, S., Mayer, G.D., Patiño, R., 2016. Effects of thyroid endocrine manipulation on sex-related gene expression and population sex ratios in Zebrafish. Gen. Comp. Endocrinol. 235, 38-47.

Schulz, R.W., França, L.R., Lareye, J.J., Le Gac, F., Chiarini-garcia, H., Nóbrega, R.H., Miura, T., 2010. Spermatogenesis in fish. Gen. Comp. Endocrinol. 165, 390-411.

Singh, R., Hamada, A.J., Agarwal, A., 2011. Thyroid hormones in male reproduction and fertility. Open Reprod. Sci. J. 3, 98-104.

Sun, B.J., Li, T., Mu, Y., McGlashan, J.K., Georges, A., Shine, R., Du, W.G., 2016. Thyroid hormone modulates offspring sex ratio in a turtle with temperature dependent sex determination. Proc. R. Soc. B 283, 1-7.

Swapna, I., Rajasekhar, M., Supriya, A., Raghuveer, K., Sreenivasulu, G., Rasheeda, M.K., Majumdar, K.C., Hagawa, H., Tanaka, H., Dutta-Gupta, A., Senthilkumaran, B., 2006. Thiourea-induced thyroid hormone depletion impairs testicular recrudescence in the air-breathing catfish Clarias gariepinus. Comp. Biochem. Physiol. Part A 144, 1-10.

Teerds, K.J., de Rooji, D.G., de Jong, F.H., van Haaster, L.H., 1998. Development of the adult-type leydig cell population in the rats is affected by neonatal thyroid hormone levels. Biol. Reprod. 59, 344-350.

Timmermans, L.P.M., Chmilevsky, D.A., Komen, H., Schipper, H., 1997. Precocious onset of spermatogenesis in juvenile carp (Cyprinus carpio L., Teleostei) following treatment with low doses of L-thyroxine. Eur. J. Morphol. 35, 344-353.

Tsutsui, K., Son, Y.S., Kiyohara, M., Miyata, I., 2018. Discovery of GnIH and its role in hypothyroidism-induced delayed puberty. Endocrinology 159, 62-68.

Wagner, M.S., Wajner, S.M., Maia, A.L., 2008. The role of thyroid hormone in testicular development and function. J. Endocrinol. 199, 351-365.

Wagner, M.S., Wajner, S.M., Maia, A.N., 2009. Is there a role for thyroid hormone on spermatogenesis. Microsc. Res. Tech. 72, 796-808.

Yoshimura, T., Yasuo, S., Watanabe, M., Iigo, M., Yamamura, T., Hirunagi, K., Ebihara, S. 2003. Light-induced hormone conversion of T4 to T3 regulates photoperiodic response of gonads in birds. Nature 426, 178-181. 